\title{
- Principais zoonoses parasitárias transmitidas por pescado - revisão
}

\section{- Main parasitic zoonosis transmitted by fish-a review}

\author{
* MariaPaula Martinez Okumura' ${ }^{1}$-CRMV-SP 11077 \\ Agar CostaAlexandrino de Pérez ${ }^{2}$-CRMV-SP 1657 \\ Antonio Espíndola Filho ${ }^{3}$-CRMV-SP6601
}

1 Professora Assistente da Disciplina de Parasitologia Veterinária do

Curso de Medicina Veterinária da Universidade Bandeirante de São Paulo - UNIBAM

2 Pesquisador Científico Instituto de Pesca - S.A.A.

3 Pesquisador Científico Instituto de Tecnologia de Alimentos (ITAL) - Setor de Pescado.

\section{RESUMO}

As zoonoses parasitárias transmitidas por pescado, ultimamente, cada vez mais vêm chamando a atenção de pesquisadores e autoridades sanitárias do mundo inteiro, por serem causas de problemas de saúde pública na população, a qual se infecta pelo consumo de pescado cru ou cozido insuficientemente. No Brasil, está havendo grande procura de pratos feitos à base de pescado cru, como "sushi" e "sashimi", devido à influência da cozinha oriental nos dias de hoje. Além disso, há dados que mostram a presença de parasitas zoonóticos nos peixes brasileiros, tanto de água doce, quanto de água salgada. Apesar disso, até o presente momento, ainda não há relatos dessas parasitoses em humanos no Brasil (com exceção da fagicolose). Acredita-se que isto se deva à falta de diagnóstico e não à ausência dessas doenças no país. Como zoonoses transmissíveis por pescado, pode-se citar a anisaquíase, a eustrongilidíase, a capilaríase, a fagicolose, a clonorquíase e a difilobotríase, dentre outras. A principal medida de prevenção é a abstinência do consumo de pescado cru ou mal cozido. Também é necessário realizar um trabalho de educação e conscientização da população, alertando-a para os potenciais perigos da ingestão de pescado cru, além de desenvolver técnicas confiáveis de inspeção e processamento do pescado infectado com parasitas, para oferecer maior segurança à população.

Unitermos: peixes, zoonoses, parasitismo, saúde pública.

\section{Introdução}

Os estudos relativos à patologia e parasitologia de peixes são campos de crescente importância no contexto da piscicultura mundial. Parece ser inevitável que as populações mundiais tornem-se cada vez mais dependentes da cultura artificial de peixes, enquanto que as populações naturais destes reduzem-se paulatinamente pela pesca predatória. Decorrentes destes fatos, as mo- dalidades artificiais praticadas de forma mais ou menos intensiva têm deparado com a escassa existência de informações sobre as enfermidades de peixes que em ambientes restritivos manifestam-se de forma mais vigorosa e disseminada. As mortalidades de peixes em geral são condicionadas por uma associação de causas endógenas e exógenas, tais como temperatura e baixo teor de oxigênio da água, com o quadro nutricional e nosológico que acomete estes animais, sendo de profunda e elemen- 
tar importância o conhecimento de tais mecanismos por parte de piscicultores, zoólogos, biólogos, zootecnistas e, principalmente, médicos veterinários (THATCHER; NETO, 1994).

Desse modo, as parasitoses têm, muitas vezes, conseqüências importantes, mas não tão evidentes: diminuição da eficiência de assimilação (o que implica um maior gasto de alimento) e da taxa de crescimento, aumento da suscetibilidade dos animais parasitados a infecções por agentes oportunistas, nomeadamente os fungos e certas bactérias (EIRAS, 1994a). Assim, segundo LEITÃO (1983), os animais parasitados não são boas fontes alimentares para as dietas das pessoas, tanto em qualidade, como em quantidade, pois as mortes por enfermidades ictioparasitárias podem diminuir muito as quantidades alimentares disponíveis para abastecer uma população. Deste modo, um peixe pode constituir-se uma excelente fonte de proteínas e de outras substâncias, mas se for proveniente de um animal parasitado, enfraquecido e com seu metabolismo alterado pela presença de parasitas, torna-se pobre e insuficiente como fonte alimentar. Esse autor também ressalta a importância do caráter zoonótico que as enfermidades de peixes podem ter.

Atualmente, dá-se maior ênfase às doenças provenientes de contaminações por organismos microbianos ou suas toxinas, havendo pouca ênfase às zoonoses ou doenças adquiridas pela ingestão de animais que abrigam estes parasitas (KHAMBOONRUANG, 1991).

Segundo SINDERMANN (1990), peixes marinhos podem ser infectados tanto por patógenos transmissíveis como não transmissíveis ao homem. Este autor considera vários agentes parasitários com importância em saúde pública, dentre eles, os anisaquídeos, os cestódeos difilobotrídeos, os trematódeos heterofídeos e o nematódeo Angiostrongylus cantonensis.

ARAMBULO; MORAN (1980) destacam a grande influência que os fatores socioculturais excercem na manutenção dos focos de zoonoses parasitárias. Os focos endêmicos continuam existindo apesar da viabilidade dos recursos para sua prevenção e controle. As práticas culturais e tradições, profundamente enraizadas, resistem a qualquer pequena mudança, mesmo que essa mudança seja direcionada para a melhoria da qualidade de vida e saúde das pessoas. Por exemplo, AMATO; BARROS (1984) citam o grande número de anisaquíase humana, que ocorre principalmente em países como Japão, Holanda, Noruega, EUA, Peru, etc., onde há o costume de ingerir peixes crus ou mal cozidos, em pratos culinários conhecidos como o "sushi" e o "sashimi" dos orientais, o "ceviche" dos hispano-americanos, ou o "green herring" dos holandeses. Além disso, o atual movimento cultural das "comidas naturais" tem influenciado também, com ênfase, o "não cozinhar demais" para a preservação dos nutrientes dos alimentos.

LEITÃO (1983) e THATCHER; NETO (1994) também destacam que algumas enfermidades de peixes têm caráter zoonótico, devendo ser alvo de maior preocupação por parte dos serviços de fiscalização sanitária do pescado destinado ao consumo humano. Desta forma, as autoridades sanitárias, os piscicultores, e os médicos veterinários devem atentar para um maior controle, desde a produção até a comercialização do pescado, para diminuir as taxas de morbidade e mortalidade das criações, melhorar cada vez mais a qualidade do pescado destinado ao consumidor e, profilaticamente, evitar a propagação das zoonoses transmissíveis por peixes.

\section{Zoonoses causadas por nematóides}

Algumas espécies de nematóides são potencialmente patogênicas para o homem, sendo o risco de infecção pronunciado em relação às que penetram na musculatura dos peixes. $\mathrm{O}$ homem parece ser quase sempre um hospedeiro anormal para os nematóides parasitas de peixes, que nessas condições, não terão possibilidade de alcançar a maturidade (EIRAS, 1994b).

Anisaquíase: A anisaquíase ocorre pela migração das larvas L3 de Anisakis spp., Phocanema spp., Terranova spp., Contracaecum spp. e Pseudanisakis spp. no interior da parede intestinal de pessoas previamente sensibilizadas a esses parasitas. As larvas encontram-se habitualmente como parasitas nas vísceras de alguns peixes como arenque e bacalhau, servindo como hospedeiros intermediários dos parasitas adultos, os quais se encontram em mamíferos, aves e peixes marinhos (AMATO; BARROS, 1984). Essa doença também é conhecida como "herring worm disease" ou "cod worm disease" ("doença do verme do arenque" ou "doença do verme do bacalhau") (CHENG, 1982). A infecção humana ocorre nos países onde existe o hábito de consumir peixe marinho cru, ligeiramente salgado ou defumado (ACHA; SZYFRES, 1986 e ACHA; SZYFRES, 1980). Também há relatos de que os anisaquídeos possam provocar reações alérgicas mesmo quando ingeridos em peixes bem cozidos (AUDICANA et al., 1997; DAY, 1997).

Segundo SINDERMANN (1990), os anisaquídeos podem ser o grupo de nematóides mais importante dos peixes marinhos, ocupando o centro em discussões sobre nematóides de peixes de mar. Esses vermes podem ser 
patogênicos para os peixes, pela sua invasão no fígado, gônadas, mesentério e musculatura corporal, onde podem resultar em uma extensa patologia, principalmente quando um grande número de parasitas está presente. Assim, muitas espécies de peixes marinhos abrigam larvas de anisaquídeos, mas apenas algumas têm grande atenção por parte dos pesquisadores, devido aos efeitos em peixes economicamente importantes ou em humanos.

SÃO CLEMENTE et al. (1996) citam que os anisaquídeos em pescado marinho utilizado como alimento têm sido uma preocupação em todo o mundo, por constituir um potencial problema de saúde pública, como também um problema estético.

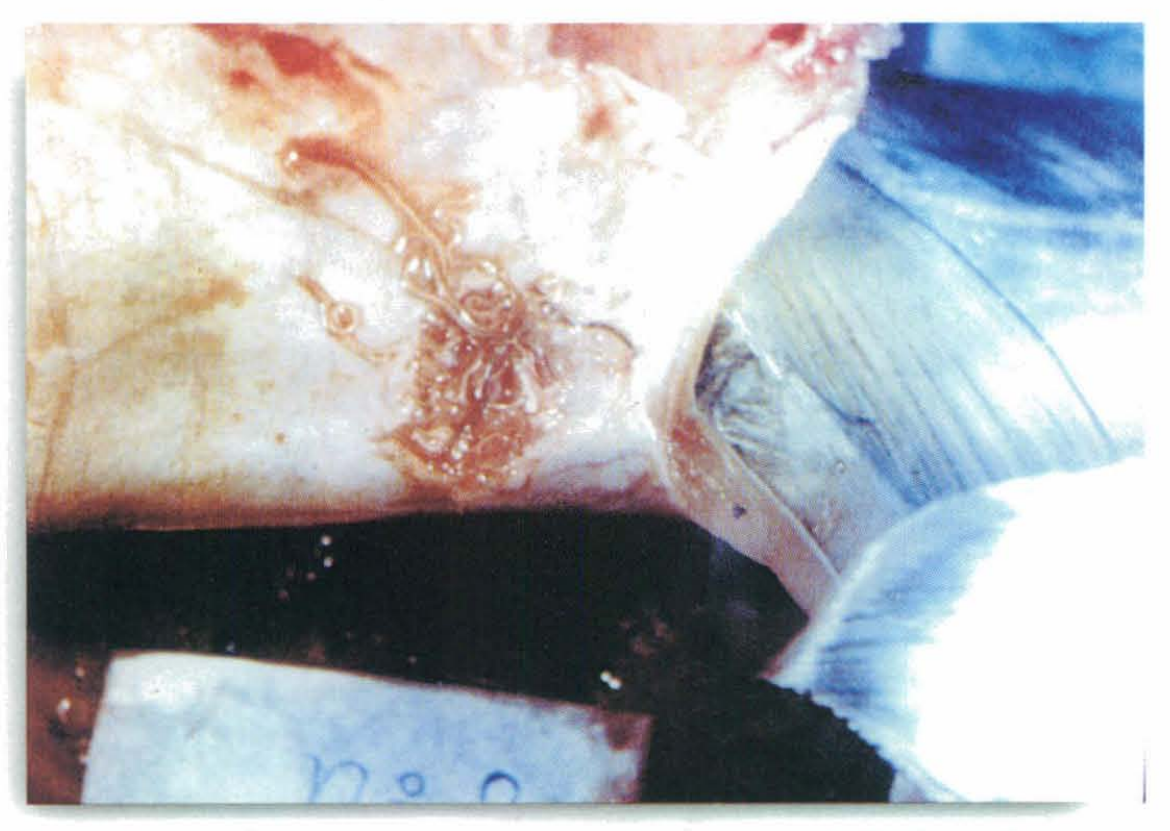

Figura 1 - Anisaquídeos em cavidade abdominal de Peixe espada (Trichiurus lepturus)

(CHENG, 1982; ACHA; SZYFRES, 1986).

Anisakis simplex é um nematóide que, na sua forma larvar, é extremamente freqüente nos peixes marinhos, enquanto que os adultos encontram-se em mamíferos marinhos, especialmente nas águas polares e nas regiões mais frias das zonas temperadas. Devido à sua importância em termos de saúde pública, a biologia dessa espécie tem sido objeto de numerosos estudos. Outro parasita importante em saúde pública é o Pseudoterranova decipiens (EIRAS, 1994b).

Distribuição e Epidemiologia: Os parasitas do gênero Anisakis encontram-se na maioria dos oceanos e mares, apesar de algumas espécies terem uma distribuição mais restrita (ACHA; SZYFRES, 1986). Embora a anisaquíase tenha sido relatada na Holanda, Japão, América do Norte e França é uma doença mais freqüente em países onde existe o hábito de ingerir peixe marinho cru ou mal cozido. No Brasil esta doença ainda não foi diagnosticada, porém, existem relatos sobre a ocorrência de anisaquídeos em peixes de importância comercial, como cavalas (Scomber japonicus), anchovas (Pomatomus saltatrix), pargos ( $\mathrm{Pa}$ grus pagrus), cangulos reais (Balistes vetula), peixes-espada (Trichiurus lepturus), (Figura 1), merluza (Merluccius gayi), xixarro (Trachurus murphyi), salmões, Thyrsites atun, e moluscos bivalves marinhos (Pecten (euvola) ziczac), em países como Brasil

Agentes Etiológicos: As larvas de nematóides que são os agentes causais da anisaquíase humana são membros de vários gêneros pertencentes à ordem Ascarida, sub-ordem Ascaridina e família Anisakidae. Atualmente, a identificação dessas larvas provenientes dos peixes para níveis genéricos e específicos não é totalmente segura. Contudo, existem dúvidas se aquelas que teoricamente poderiam ser responsáveis pela anisaquíase humana pertencem aos gêneros Anisakis, Belanisakis, Phocanema, Porrocaecum, Paradujardinia, Pseudoterranova, Cloeoascaris, Phocascaris e Contracaecum. As espécies pertencentes a estes gêneros são agentes potenciais da anisaquíase humana, e têm nos mamíferos marinhos e aves seus hospedeiros definitivos naturais. A identificação exata desses parasitas só é possível pelo exame de vermes adultos sexualmente maduros
(Rio de Janeiro, São Paulo), Chile e Espanha (TORRES et al., 1978; AMATO; AMATO, 1982; REGO; SANTOS, 1983; REGO et al., 1983; AMATO; BARROS, 1984; WITTNER et al., 1989; BARROS, 1994; SÃO CLEMENTE et al., 1995; ADROHER et al., 1996; LUQUE, 1996). Assim, embora a anisaquíase em humanos tenha sido primariamente restrita a países com costume de ingerir peixe marinho cru ou mal cozido, o potencial para infecções humanas existe no mundo todo, na medida em que os parasitas causadores têm distribuição mundial (CHENG, 1982).

A Doença nos Animais: As larvas de anisaquídeos podem causar alterações patológicas em várias espécies de peixes marinhos. A parasitose pode afetar vários órgãos e as larvas podem chegar a centenas em cada peixe. O órgão mais afetado é o fígado e a sua alteração 
mais comum é a atrofia (Figura 2). Além disso, há uma perda de peso significativa. Ainda existem dúvidas se o dano provocado pelos anisaquídeos é pela sua presença em si ou pela secreção de toxinas (CHENG, 1982; ACHA; SZYFRES, 1986). Numerosas espécies, muitas das quais de grande interesse comercial ( $\mathrm{Ga}$ dus morhua parece ser o hospedeiro mais freqüente), foram encontradas parasitadas por $P$. decipiens, e a prevalência e a intensidade da infecção tende a ser maior nos exemplares de espécies piscívoras bentônicas de grande tamanho. As larvas podem viver no músculo durante vários anos (EIRAS, 1994b).

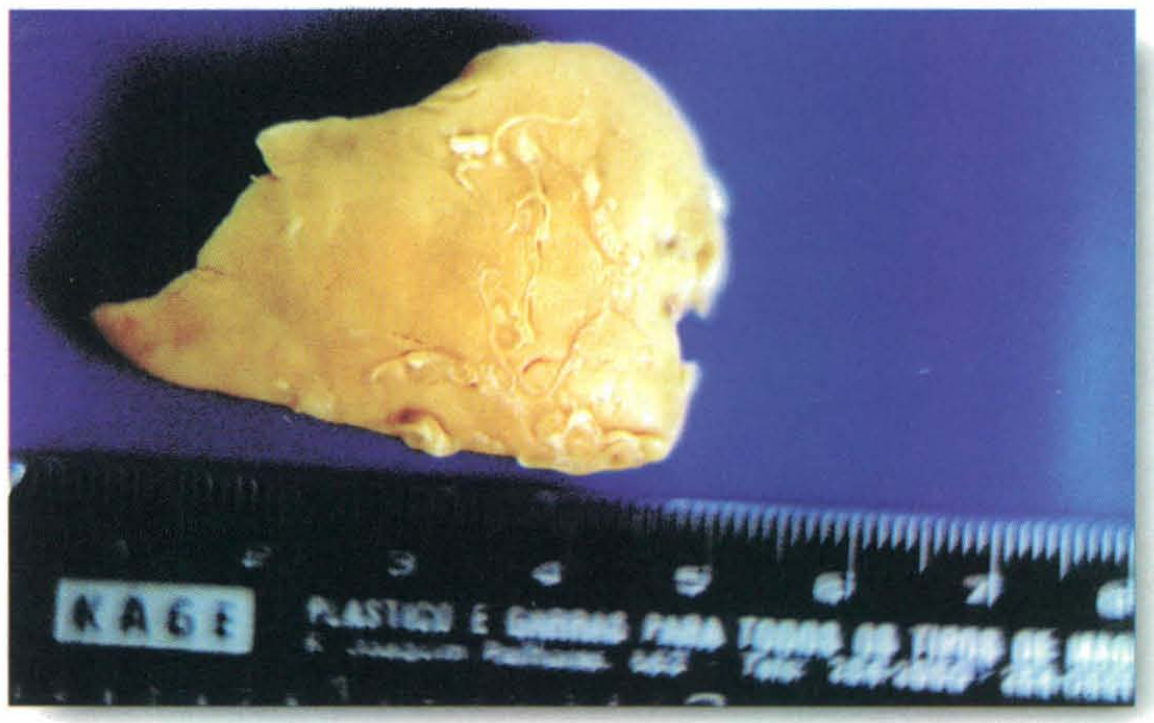

Figura 2 - Figado de Olho-de-cão (Priacanthus arenatus) com presença de Anisakis sp.

A Doença em Humanos: A anisaquíase ocorre quando o homem acidentalmente ingere larvas de anisaquídeos, penetrando no trato digestivo, e causa um granuloma eosinofílico (KATES et al., 1973), que pode ocorrer na parede gástrica e intestinal, sendo o estômago o local mais freqüente. Os sintomas clínicos incluem dor gástrica ou intestinal. Geralmente ocorre uma leucocitose média, embora eosinofilia não seja aparente. Não há tensão anormal dos músculos abdominais e não há febre. De acordo com clínicos experientes, esses sinais são importantes na distinção da anisaquíase de apendicite aguda e de obstrução interna (CHENG, 1982).

As larvas que se localizam fora do tubo digestivo provocam a formação de granulomas eosinofílicos, ocorrendo dores estomacais e vômitos cerca de 4 a 6 horas após a ingestão de larvas. No estômago, as larvas invadem a mucosa e submucosa, criando túneis e galerias nos tecidos claramente observados em microscopia de varredura (EIRAS, 1994b).

Há relatos de casos não típicos da presença de larvas de anisaquídeos no organismo humano. LITTLE; MacPHAIL (1972) relataram o caso de uma L3 de anisaquídeo (Phocanema spp.) em um aneurisma da artéria ilíaca comum. KATES et al. (1973), LITTLE; MOST (1973), CHITWOOD (1975), LICHTENFELS; BRANCATO (1976) e KLIKS (1983) relatam casos em que essa larva é expelida via oral, geralmente após o paciente sentir prurido na garganta e tossir. OSHIMA (1987) cita que larvas de $A$. simplex podem localizar-se também no tecido subcutâneo e há um caso relatado de provável anisaquíase pulmonar. Segundo KATES et al. (1973), a habilidade de a larva de nematóide anisaquídeo causar doença em um hospedeiro anormal (acidental), como o homem, depende de dois fatores, isto é, da sua habilidade em permanecer viva e da sua capacidade de invadir tecidos.

Atualmente, pesquisadores estão relatando casos de reações alérgicas provocadas pela ingestão de peixes bem cozidos, mas infectados. A existência do potencial alergênico de A. simplex fez com que os pesquisadores considerassem esse agente no diagnóstico diferencial de urticária em humanos com relatos de ingestão de pescado. A severidade das reações de hipersensibilidade por alimento com antígenos ingerido varia desde uma leve urticária até o choque anafilático (AUDICANA et al., 1997; DAY, 1997).

Prevenção e Controle: No homem, a anisaquíase pode ser prevenida pela abstinência do consumo de peixe cru ou mal cozido (CHENG, 1982; ACHA; SZYFRES, 1986). Outros modos de prevenir estas zoonoses seria escolher e eliminar peixes infectados por nematóides ou a remoção dos nematóides do peixe, por exemplo, à mão, colocando o peixe sobre uma mesa iluminada ("candle table"); e aplicar técnicas para matar os nematóides na carne do peixe (HUSS, 1997).

Eustrongilidíase: A eustrongilidíase é uma infecção parasitária provocada por Eustrongylides spp., adquirida pelo consumo de "sushi", (WITTNER et al., 1989).

Agente Etiológico: Eustrongylides Jagerskiold, 1909, são parasitas nematóides da família Dioctophymatoidae Railliet, 1915, cujos adultos habitam tipicamente a mucosa do esôfago, pró-ventrículo ou intestino de aves 
aquáticas. Os estágios larvares ocorrem nos tecidos de peixes, anfíbios e répteis (PANESAR; BEAVER, 1979; EBERHARD et al., 1989; EIRAS, 1994b). As larvas desse parasita emergem do corpo do peixe hospedeiro para a superfície deste em temperaturas iguais ou maiores a $40^{\circ} \mathrm{C}$. Esse comportamento pode representar uma adaptação para facilitar uma rápida infecção de um hospedeiro de sangue quente após a ingestão de um peixe infectado (COOPER et al., 1978).

Distribuição e Epidemiologia: E. tubifex e $E$. ignotus ocorrem nos EUA na costa do Atlântico, do Canadá à Flórida. Todos os casos humanos ocorridos nos EUA foram em Maryland e New Jersey, próximos à costa do Atlântico (EBERHARD et al.,1989). COOPER et al. (1978) constataram a presença de E. tubifex no lago Erie (EUA) em "catfish" (Ictalurus punctatus), em miragaia (Aplodinotus grunniens) e em perca (Micropterus dolomieui). REGO (1988) cita que Eustrongylides são encontrados no estado larvar em espécies de peixes dulciaquícolas no estado selvagem, embora não tenha conhecimento de casos deste parasita em peixes de piscicultura no Brasil, com exceção da traíra (Hoplias malabaricus). Mesmo assim, é certo que existam nos locais de piscicultura extensiva (açudes, lagos e lagoas). Segundo WITTNER et al. (1989), a infecção humana com Eustrongylides após o consumo de "sashimi" ou "sushi" é incomum. Nem todos os peixes que servem como hospedeiros intermediários para esse parasita são conhecidos. Assim, as pessoas que costumam ingerir peixe cru ou cozido insuficientemente podem estar correndo certo risco para a saúde. PANESAR; BEAVER (1979) sugerem que sapos e peixes são importantes hospedeiros paratênicos.

A Doença nos Animais: Existem relatos contraditórios quanto à patogenia das larvas nos peixes. Vários autores verificaram que as modificações histopatológicas relacionadas com as larvas resumiam-se ao encapsulamento das mesmas por tecido conjuntivo, enquanto que os tecidos adjacentes do hospedeiro sofriam alterações discretas (EIRAS, 1994b). Já PAPERNA (1974) apud EIRAS (1994b) observou a existência de grande quantidade de tecido lipídico envolvendo as cápsulas de Eustrongylides sp. no fígado de Haplochromis sp. e Bagrus docmac. REGO (1988) relata que, em peixes, as larvas podem ser encontradas livres ou encapsuladas nos músculos esqueléticos e vísceras, envoltas por camadas de tecido conjuntivo e infiltrado com moderada quantidade de linfócitos e macrófagos. BURSEY (1982) apud EIRAS (1994b) relata um caso de encistamento de E. tubiflex na derme de A. rostrata. Em uma infecção experimental de Eustrongylides sp. em coelhos brancos Nova Zelândia, apesar de o exame post-mortem após 24 horas da inoculação revelar que as larvas tinham migrado através das paredes do esôfago e do estômago, e larvas viáveis terem sido recuperadas das cavidades pleural e peritoneal, bem como dos conteúdos gástricos. As necropsias realizadas em diferentes intervalos de tempo pós-inoculação mostraram que a migração das larvas produziram uma peritonite multifocal e granulomas múltiplos no fígado (SHIRAZIAN et al., 1984). Em exemplares de pequenas dimensões de Haplochromis sp., a parasitose por um exemplar pode interferir com o desenvolvimento normal dos óvulos, e por dois ou mais, pode resultar na destruição do ovário e, direta ou indiretamente, impedir a reprodução (PAPERNA, 1974 apud EIRAS, 1994b).

A Doença em Humanos: EBERHARD et al. (1989) descreveram o caso de um paciente com intensa dor abdominal no quadrante baixo direito, onde dois grandes nematóides foram removidos da cavidade peritoneal, sendo identificados como larvas de quarto estágio de Eustrongylides. Esse paciente tinha histórico de ter engolido pequenas carpas vivas enquanto pescava. WITTNER et al. (1989) relataram o caso de um paciente com histórico de dor no quadrante baixo direito. Após ser diagnosticada apendicite, o paciente foi operado, e, após a incisão abdominal ser fechada, um parasita avermelhado de $4,2 \mathrm{~cm}$ de comprimento surgiu movendo-se nos panos cirúrgicos. O tamanho e a morfologia do parasita indicou que era provavelmente uma larva de quarto estágio do gênero Eustrongylides, de espécie indeterminada. O paciente adquiriu o parasita pela ingestão de "sushi" e "sashimi" um mês antes de apresentar sintomatologia clínica.

Prevenção e Controle: Nenhuma informação sobre a tolerância à temperatura de Eustrongylides é disponível (WITTNER et al., 1989). Mesmo assim, SHIRAZIAN et al. (1984), WITTNER et al. (1989) e EBERHARD et al. (1989) recomendam a abstinência de peixe cru ou insuficientemente cozido para a prevenção desta doença. COOPER et al. (1978) indicam que mantendo o pescado no frio ou eviscerando o pescado assim que é embarcado, eliminará a ativação das larvas e a subseqüente migração para a musculatura do animal. A manutenção dos peixes no "deck" quente do barco no verão, faz com que haja a invasão da musculatura do peixe por larvas de Eustrongylides tubifex. 
Capilaríase: A capilaríase intestinal humana é uma nova doença helmíntica causada pelo nematóide Capillaria philippinensis (WATTEN et al., 1972).

Agente Etiológico: O agente etiológico da capilaríase intestinal é Capillaria philippinensis. Existem mais de 200 nematóides do gênero Capillaria, mas apenas alguns foram encontrados no homem e somente $C$. philippinensis tem causado razoável problema de saúde pública (WATTEN et al., 1972). A fêmea mede apenas 2,5 a 4,3 mm de comprimento e o macho é ainda menor (ACHA; SZYFRES, 1986). Segundo GEORGI (1988), fica parcialmente incrustado nas membranas mucosas digestivas.

Distribuição e Epidemiologia: A capilaríase intestinal por $C$. philippinensis foi identificada pela primeira vez, em 1963 nas Filipinas. Em 1967, foram registrados mais de mil casos, com letalidade de $10 \%$. Sem dúvida, a prevalência da infecção parece relativamente baixa, já que de 4.000 habitantes da área endêmica examinados durante a epidemia de 1967 , menos de $3 \%$ possuíam ovos do parasita nas fezes. Fora da área endêmica das Filipinas, foram diagnosticados dois casos na Tailândia (WATTEN et al., 1972; ACHA; SZYFRES, 1986). $\mathrm{O}$ homem é o único hospedeiro definitivo conhecido de C. philippinensis. Devido aos graves efeitos patológicos produzidos nesse hospedeiro, acredita-se que a relação parasita-homem seja bastante recente. Há suspeitas de que possa existir outro animal que atue como hospedeiro definitivo, mas até agora não foi possível identificálo, se é que existe. A fonte principal e o modo de infecção relacionam-se com a ingestão de pescado (hospedeiro intermediário) cru, que contém a larva infectante. A contaminação dos cursos de água com excretas humanas assegura a perpetuação do ciclo. Também é possível que exista a transmissão direta de um humano para outro (BANZÓN, 1982).

A Doença nos Animais: $C$. philippinensis não foi encontrado em animais terrestres, mas suspeita-se que possa existir um reservatório animal, devido à pouca adaptação do parasita no homem. A infecção experimental em primatas do gênero Macaca ou em ratos silvestres transcorre de modo assintomático. Em cervos, a infecção manifesta-se com sintomatologia semelhante à do homem (BANZÓN, 1982).

A Doença em Humanos: A capilaríase intestinal por C. philippinensis é uma doença grave e mortal se não tratada a tempo. A maioria dos pacientes têm de
20 a 45 anos de idade e predominam os do sexo masculino. A doença inicia-se com sintomas pouco significativos, como borborigmos e dores abdominais vagas. Após duas ou três semanas, há diarréia intermitente e perda de peso, e conforme a doença vai progredindo, esses sintomas tornam-se mais evidentes. A função gastrointestinal é gravemente afetada; além disso, ocorre má-absorção e perda de grande quantidade de proteínas, lipídeos e minerais. A morte ocorre como consequência de falha cardíaca ou infecção intercorrente, após algumas semanas ou poucos meses do início da sintomatologia. Ademais, há outros sintomas, como fadiga muscular, cansaço, e em casos mais graves, ocorre severa fadiga muscular, edema, caquexia e morte (FRESH et al., 1972; WATTEN et al., 1972; ACHA; SZYFRES, 1986). Em autópsias realizadas em dez filipinos adultos, mortos pela infecção intestinal de $C$. philippinensis, todos os corpos estavam severamente emaciados e o turgor da pele estava bastante reduzido. Foi encontrado transudato nas cavidades pericárdica, pleural e peritonial. Haviam um grande número de adultos, larvas e ovos do parasita no intestino delgado, particularmente no jejuno. Os parasitas adultos estavam parcialmente enterrados na mucosa adjacente do lumem. As formas larvares estavam freqüentemente próximas aos adultos na mucosa. Em menor número, parasitas foram encontrados na laringe, esôfago, estômago e cólon, embora não enterrados na mucosa. Havia vacuolização dos músculos estriados, indicativo de hipopotassemia, e também das células tubulares proximais do rim (FRESH et al., 1972).

Prevenção e Controle: Nas áreas endêmicas, a capilaríase intestinal pode ser prevenida pela abstinência do consumo de pescado cru ou insuficientemente cozido. Os pacientes devem ser tratados com tiabendazol ou mebendazol, tanto para a cura como para diminuir a disseminação dos ovos do parasita. $\mathrm{O}$ destino higiênico dos excretas humanos é muito importante também (ACHA; SZYFRES, 1986; FAUST et al., 1987).

\section{Zoonoses causadas por trematóides (Trematoda: Digenea)}

As zoonoses provocadas por trematóides de peixes são um grande problema de saúde pública, com mais de 50 milhões de pessoas afetadas no mundo todo, principalmente no oeste e sudoeste da Ásia (SANTOS, 1995).

Em Digenea encontra-se a maior parte dos parasitas de peixes que tem sido descrita ocorrendo no homem. Entre eles incluem-se Clonorchis sinensis, Opistorchis 
felineus, O. viverrini, Heterophyes spp., Metagonimus spp., Diplostomum spathaveum, Pygidiopsis summa, Stellantchasmus falcatus, Procerovum varium, Haplorchis spp., Nanophyetus schickhobalowi, Cryptocotyle lingua, Gonadosdasmius sp., Metorchis conjunctus, Echinoschasmus perfoliatus, Echinostoma hortense, Clinostomum complanatum, Pseudamphistomum truncatum e Isoparorchis hypselobagri. Muitas vezes, as infecções são raras e ocasionais, como acontece com Diplostomum spathaceum e Clinostomum complanatum, e o significado patogênico não é geralmente importante, exceto no caso de infecções abundantes. No caso da última espécie, a parasitose humana tem sido associada à afecção conhecida por laringofaringite parasitária que, nas formas graves, pode conduzir à morte por asfixia (EIRAS, 1994b).

Fagicolose: É a infecção causada por Phagicola longa, cuja especificidade parasitária é baixa, que associada à ingestão de carne de tainhas, quando não submetidas à cocção, determina sua importância para a clínica de pequenos animais, animais silvestres e em saúde pública (BARROS, 1993). Assim, CASTRO (1994) destaca que além do papel que a infecção por Phagicola pode representar em saúde pública, deve-se também voltar a atenção para os prejuízos que a infecção das taínhas pode vir a representar em relação à produção animal, que corresponde a outra área de grande responsabilidade do médico veterinário.

Agente Etiológico: Phagicola longa é um trematódeo digenético, pertencente à família Heterophyidae, que possui uma baixa especificidade parasitária, havendo muitos relatos na literatura de diferentes espécies de aves e mamíferos por ele naturalmente parasitados. Assim, a grande versatilidade que os heterofídeos apresentam em adaptar-se ao intestino de diferentes espécies de hospedeiros, sejam eles aves ou mamíferos, confere-lhes a possibilidade de ocorrência também na espécie humana (BARROS, 1993).

Distribuição e Epidemiologia: Phagicola lon$g a$ e outras espécies desse gênero foram relatadas em vários locais do continente americano, inclusive no Brasil (CHIEFFI et al., 1990). SARAIVA (1991) relata a presença de metacercárias de $P$. longa em todos os exemplares de tainha (Mugil curema) frescos examinados, provenientes da Enseada de Patanemo, na Venezuela. ASH (1962) relatou a presença de $P$. longus no Havaí em cães e gatos.
Segundo DIAS; WOICIECHOVSKI (1994), houve a constatação da presença desse parasita em mugilídeos da região de Cananéia e Registro (SP), com 100\% de prevalência em peixes com mais de $4 \mathrm{~cm}$ de comprimento total. Em amostragem de peixes mugilídeos provenientes da frota comercial da Baixada Santista (Santos e Guarujá - SP), foi observada a presença de metacercárias encistadas de heterofídeos, identificados como Phagicola longus, em 100\% das amostras (ANTUNES; DIAS, 1994).

Segundo CASTRO (1994), das espécies do gênero Phagicola descritas no Brasil, Phagicola lon$g a$ (também denominada $P$. longus), tem se destacado das demais por ser a única, até o momento, que parece capaz de infectar o homem entre outros animais. Parece não haver dúvidas de que a transmissão de Phagicola em nosso meio faça-se pelo consumo de tainha (Mugilidae) crua, de modo que esse pescado passa a representar um reservatório da infecção para o homem e para outras espécies animais que dele se alimentam, já que Phagicola parece não requerer alta especificidade do hospedeiro (CHENG, 1973). A infecção por Phagicola é uma zoonose ainda emergente e carente de estudos de uma forma geral, particularmente no que se refere à relação parasito-hospedeiro. Faz-se necessário que os profissionais envolvidos no estudo de zoonoses, desenvolvam pesquisas que possibilitem investigar todos os possíveis determinantes relacionados com sua cadeia de transmissão (CASTRO, 1994).

A Doença nos Animais: Segundo BARROS (1993), o parasitismo por P. longus, tendo como hospedeiros aves piscívoras e mamíferos, provoca alterações patológicas que tendem a manifestações subclínicas e de prognóstico favorável.

Em um estudo experimental em que metacercárias viáveis de P. Longus foram administradas a um macaco (Cebus apella), que começou a eliminar ovos do parasita nas fezes, mostrando que esta espécie de macaco é suscetível à infecção por Phagicola (CONROY; PEREZ, 1985).

BARROS; AMATO (1993) infectando experimentalmente cães (Canis familiaris), gatos (Felis domestica) e micos (Callithrix jacchus), observaram que o parasita tem preferência pelo jejuno dos hospedeiros. Os digeneos geralmente estavam com a região anterior localizada na região fúndica da mucosa intestinal, provocando lesões hemorrágicas puntiformes em todo o intestino delgado de cães e gatos, enquanto nos micos observaram-se essas lesões no terço médio do 
jejuno. BARROS; AMATO (1992) também infectaram experimentalmente gatos com metacercárias presentès nas vísceras de tainhas portadoras de $P$. longus. Os animais apresentaram alterações clínicas com sintomatologia de ascite e alteração na consistência das fezes. A histopatologia revelou um quadro de enterite subaguda.

Em tainhas, metacercárias encistadas de $P$. longus foram encontradas no coração, fígado e tecido mesentérico de peixes com $26 \mathrm{~mm}$ ou mais (CONROY et al., 1985). ALEXANDRINO et al. (1992) examinaram amostras de baço de tainhas adultas (Mugil platanus), provenientes de Cananéia (SP), onde se observaram alterações histológicas no parênquima do órgão, revelando a presença de cistos arredondados de vários tamanhos e revestidos por abundante quantidade de tecido conjuntivo denso. O exame parasitológico revelou que havia a presença de larvas de trematóides digeneos, provavelmente Phagicola spp.

A Doença em Humanos: Quando o homem ingere a carne de uma tainha infectada por Phagicola longus, o parasita pode nele desenvolver-se, causando sintomas típicos da parasitose, como cólicas, flatulência, diarréias, emagrecimento e outros estados característicos de verminoses em geral (CHIEFFI et al., 1990; DIAS; WOICIECHOVSKI, 1994). CHIEFFI et al. (1990) relataram o caso de uma paciente com histórico de ingestão de pescado cru preparado com tainha $(\mathrm{Mu}$ gil spp.) na região de Cananéia (SP). Ao exame físico, a paciente revelou estar com dores no quadrante baixo direito na palpação, e hipermotilidade intestinal. No exame de fezes, observou-se a presença de ovos de Phagicola (provavelmente $P$. longus), com eliminação de 120 ovos por grama de fezes. O hemograma apenas mostrou uma discreta eosinofilia. A paciente foi tratada com praziquantel.

Prevenção e Controle: A abstinência de ingestão de carne de tainha crua ou insuficientemente cozida é o principal meio de prevenção (BARROS; AMATO, 1992; CHIEFFI et al., 1990; BARROS, 1993; ANTUNES; DIAS, 1994; DIAS; WOICIECHOVSKI, 1994). A transferência de alevinos de tainha com comprimento total entre 2,0 e $4,0 \mathrm{~cm}$ para água doce, possibilita a criação de peixes isentos de Phagicola. Esses achados levam a crer que a aclimatação de tainhas em água doce pode atuar com mais um recurso no controle da infecção por Phagicola nos hospedeiros vertebrados, inclusive o homem (DIAS; WOICIECHOVSKI, 1994).
Tainhas refrigeradas a $8^{\circ} \mathrm{C}$ em caixas com gelo constituem um alto risco para o consumidor humano, pois contém um grande número de metacercárias de $P$. longa, as quais são viáveis mesmo após seis dias em refrigeração, podendo infectar o hospedeiro final no momento de preparar o produto, se este não for processado adequadamente. Além disso, as metacercárias em tainhas congeladas a $-2^{\circ} \mathrm{C}$, mantém-se vivas por aproximadamente 12 horas. Tratamentos térmicos a $100^{\circ} \mathrm{C}$ durante 30 minutos ou a $200^{\circ} \mathrm{C}$ durante 15 minutos são suficientes para inativar completamente as metacercárias presentes nas tainhas (Mugil curema). Em tainhas defumadas a $121^{\circ} \mathrm{C}$ por 3 horas verifica-se que as metacercárias estão inativadas. Assim, recomenda-se que o consumidor ingira as tainhas bem cozidas, não as consumindo cruas ou semi-cruas, além de eliminar completamente as vísceras da tainha antes de cozê-las (SARAIVA, 1991).

ANTUNES et al. (1993) estudaram os efeitos da ionização gama para controle de Phagicola longus em tainhas em condições de estocagem e no consumo cru. A dose para controle desse parasita é $4.0 \mathrm{kGy}$. Essa dose também controla outras metacercárias encontradas no parati-pema (Mugil sp.), sem alterar características de odor, coloração, consistência da musculatura e abdômen ou a aparência da tainha tratada durante os primeiros dias de armazenagem. Esse é o período geralmente usado para a preparação e consumo de "sashimi". DIAS; WOICIECHVSKI (1994) recomendam que sejam desenvolvidas pesquisas para conhecimento dos métodos de estocagem dos mugilídeos na $P$. longa e tratamentos tecnológicos para seu controle.

Clonorquíase e Opistorquíase: A clonorquíase é uma doença dos ductos biliares, causada por trematóides. A opistorquíase é uma doença causada por pequenos trematóides de gatos e outros mamíferos piscívoros, conhecidos como Opisthorchis felineus. A biologia desses parasitas, as características da doença e os métodos de controle são essencialmente os mesmos que correspondem à clonorquíase (BENESON, 1987). Os Opisthorchiidae $O$. felineus, $O$. viverrini e Clonorchis sinensis são os que ocasionam mais graves conseqüências no homem e ocorrem freqüentemente em vários países asiáticos (EIRAS, 1994b).

Agentes Etiológicos: O agente etiológico da clonorquíase é o trematóide hepático da China, Clonorchis sinensis, referido pela primeira vez nos canais biliares de um carpinteiro chinês autopsiado em Calcutá (FAUST et al., 1987). Segundo GEORGI (1988), os parasitas da fa- 
mília Opisthorchiidae possuem útero e ovário situados anteriormente aos testículos, não havendo bolsa do cirro, e o poro genital situa-se em posição imediatamente anterior à ventosa ventral.

A opistorquíase é causada por Opisthorchis felineus, originariamente isolado do gato na Itália, e alguns anos mais tarde, do homem, na Sibéria (FAUST et al., 1987). O parasita adulto assemelha-se a $C$. sinensis nas dimensões e aspecto geral. Uma diferença notável está no menor tamanho e ramificação dos testículos. Os ovos de $O$. felineus são mais estreitos (30 por $11 \mu$ ), mas as outras características são semelhantes às do Clonorchis (LEITÃO, 1983; FAUST et al., 1987). Outro agente da opistorquíase é $O$. viverrini, que é estritamente relacionado com $O$. felineus. É endêmico no norte da Tailândia, onde cerca de $25 \%$ da população está infectada (FAUST et al., 1987).

Distribuição e Epidemiologia: A zona endêmica-enzoótica de $C$. sinensis estende-se desde o Japão até o Vietnã (BENESON, 1987; FAUST et al., 1987). Assim, C. sinensis é comum no Japão, Coréia, China, Hong Kong e Indochina, distribuição geográfica que coincide com a do primeiro hospedeiro intermediário, $\mathrm{Pa}$ rafossalurus manchouricus, e espécies estreitamente aparentadas. Este Digenea infecta milhões de pessoas e em certas áreas da China cerca de $100 \%$ dos habitantes estão parasitados (EIRAS, 1994b).

RIM et al. (1996) relata que há grandes taxas de infecção de metacercárias, como $C$. sinensis, em peixes de água doce em rios da Coréia. Essas metacercárias encontradas são infectantes para o homem. $O$. felineus encontra-se largamente distribuído no leste e sul da Europa, assim como na Rússia asiática e foi isolado do homem na Índia (FAUST et al., 1987). O. viverrini ocorre no norte da Tailândia, no Laos, na Malásia e provavelmente em outros países do sudeste da Ásia (BENESON, 1987; FAUST et al., 1987). A doença ainda pode ocorrer em outras partes do mundo devido a casos importados dos imigrantes da Ásia (BENESON, 1987). As infecções humanas por $O$. felineus e $O$. viverrini são também muito abundantes, calculando-se que apenas na Tailândia existam cerca de 4 milhões de pessoas infectadas (EIRAS, 1994b).

Segundo EIRAS (1994b), BENESON (1987) e FAUST et al. (1987), a infecção é contraída por ingestão de peixe de água doce cru, salgado, curtido, defumado ou desidratado contaminado por metacercárias. A intensidade de infecção das metacercárias de $C$. sinensis no organismo do peixe é diferente, resultante do comportamento da larva nesse hospedeiro (RIM et al., 1996). As metacercárias de $C$. sinensis podem ser encontradas em mais de 80 espécies de peixes (bem como em três de camarão de água doce), nas quais encistam no tecido conjuntivo subcutâneo e músculo (EIRAS, 1994b).

Os pesquisadores estão começando a mostrar claramente o impacto devastador que a infecção por Opisthorchis viverrini teve na população Laos-descendente do noroeste da Tailândia, que tem grande afinidade em ingerir carne mal cozida e peixes, entre os quais o hospedeiro intermediário do parasita: os peixes ciprinídeos (HASWELL-ELKINS et al., 1992). Os opistorquídeos exibem uma especificidade em baixíssimo grau quanto aos hospedeiro. Assim, cada espécie é capaz de infectar muitas espécies de mamíferos piscívoros (GEORGI, 1988).

O homem é o hospedeiro definitivo mais adequado para $C$. sinensis (EIRAS, 1994b). Como reservatórios da doença estão o homem, o gato, o cão, o suíno e outros animais. Seu período de incubação é indeterminado, variando com o número de parasitas presentes. Os indivíduos parasitados podem expulsar ovos viáveis durante 30 anos, embora não haja transmissão entre uma pessoa e outra (BENESON, 1987). Em casos de epidemia, recomenda-se localizar a fonte do pescado infectado, sendo possível que lotes de pescado seco ou em salmoura sejam as fontes em zonas não-endêmicas (BENESON, 1987).

A Doença no Homem e nos Animais: Os sintomas das infecções variam de acordo com as espécies que os estão causando. De qualquer modo, no caso de infecções crônicas hepáticas, pode haver danos nos ductos biliares, problemas gastrointestinais, icterícia, fadiga e colangiocarcinoma (SANTOS, 1995). Quando adulto e localizado nos canais biliares, $C$. sinensis provoca hiperplasia do epitélio biliar, com subseqüente fibrose pericanalicular densa. O número de parasitas pode atingir vários milhares e, praticamente todos os canais biliares terminais apresentam espessamento fibroso das paredes, com necrose por compressão do parênquima hepático adjacente (FAUST et al., 1987).

Segundo LEITÃO (1983), BENESON (1987) e GEORGI (1988), a infecção com pequeno número de opistorquídeos é geralmente assintomática, mas a infecção crônica com uma carga parasitária maciça pode conduzir a uma severa insuficiência hepática, como consequiência da irritação local dos ductos biliares pelos parasitas. A infecção por $O$. viverrini provoca diarréia, dilatação e amolecimento do fígado, icterícia e febre moderada. Os sintomas intensificam-se progressivamente (BENESON, 1987; FAUST et al., 1987). Também pode ocorrer opistorquíase pancreática, onde o parasita causa inflamação dos condutos da glândula (LEITÃO, 1983). 
Prevenção e Controle: O modo mais óbvio de se evitar essas parasitoses é a abstenção de consumo de peixe cru. No entanto, hábitos culturais arraigados fazem supor que a diminuição da parasitose por essa via será extremamente improvável, senão impossível. O controle dos primeiros hospedeiros intermediários será o processo de eleição para diminuição da parasitose, que deverá ser encarado mediante um controle biológico e não pelo emprego de produtos químicos que podem afetar os peixes que, nas regiões mais atingidas, constituem um dos mais importantes recursos alimentares das populações (EIRAS, 1994b).

A profilaxia consiste em cozinhar adequadamente todo o pescado destinado à alimentação humana, o que representará uma proteção eficaz das populações (BENESON, 1987; FAUST et al., 1987). BENESON (1987) ainda recomenda o congelamento a $-10^{\circ} \mathrm{C}$ durante 5 dias no mínimo, ou o armazenamento durante várias semanas em solução saturada com sal, de todos os peixes de água doce. Além disso, também é importante realizar a educação sanitária da população sobre os perigos da ingestão do pescado cru ou preparado inadequadamente, e a necessidade da destinação correta das fezes para não contaminar as fontes de alimentação dos peixes, proibindo também o uso de fezes para adubação de viveiros de peixes. É uma doença que se deve notificar as autoridades locais de saúde quando ocorrer. Assim, HASWELLELKINS et al. (1992) comentam que tradições culturais e alimentares bem estabelecidas são extremamente difíceis de mudar; desse modo, a mídia disponível sobre saúde pública combinada com tratamento extenso com praziquantel podem efetivamente estancar o consumo de peixe cru, por mais demorado que possa parecer.

SANTOS (1995) cita que modelos de controle de zoonoses provocadas por trematóides de peixes foram estabelecidos em países endêmicos, como China, Japão, Coréia, Tailândia e Rússia, através da detecção e o tratamento do paciente, educação sanitária, legislação sobre a eliminação dos excretas e participação da comunidade. Como exemplo, SORNMANI (1987) relata o caso da Tailândia, onde a educação sanitária na prevenção e controle da opistorquíase raramente resultou em sucesso, embora após 3 anos da implementação de um programa de controle com a participação da comunidade, a opistorquíase foi controlada, além de iniciar outros cuidados primários de saúde, como a provisão de água potável medicamentos essenciais, e a construção de banheiros mais aperfeiçoados para a população. Como medidas internacionais de controle, deve haver o controle do pescado ou de produtos da pesca importados de zonas endêmicas (BENESON, 1987). Apesar disso, países onde essas zo- onoses são endêmicas, a inspeção de pescado e serviços de segurança alimentar em geral não estão interessados particularmente no controle de produtos comercializados apenas dentro do mercado doméstico; assim, o mercado doméstico ou local é geralmente negligenciado e o controle dessas zoonoses tem sido negligenciado até hoje (SANTOS, 1995). SANTOS (1995) recomenda o uso do sistema Hazard Analysis and Critical Control Point (HACCP), no qual se baseia em dois objetivos principais: a prevenção da infecção do peixe com os estágios infectantes dos parasitas; e a inativação do parasita no peixe infectado (matando o parasita). Quanto aos animais, devese evitar a sua alimentação com peixe cru, principalmente nos locais onde existam os primeiros e segundos hospedeiros intermediários (LEITÃO, 1983).

\section{Zoonoses causadas por cestóides}

Os plerocercóides de espécies de tênias pseudofilídeas, dentre as quais o gênero mais importante é Diphyllobothrium, podem alcançar o homem que ingere pescado cru. A biologia deste grupo engloba dois grupos de hospedeiros intermediários: os copépodes e os peixes. Os plerocercóides de outras espécies distintas de Diphyllobothrium são incapazes de maturar até a fase de tênia adulta no homem, mas migram na pele ou no tecido subcutâneo, determinando a doença conhecida como esparganose. A água que contém procercóides ou copépodes infectados e a carne de outros animais são origens mais freqüentes desta doença do que o pescado (INFORME..., 1975).

Difilobotríase: A difilobotríase é uma endoparasitose humana freqüente, causada por Diphyllobothrium spp., principalmente onde diversos peixes (como salmonídeos, por exemplo) atuam como hospedeiros intermediários e é freqüente o consumo cru destes peixes ou de seus produtos, ocorrendo em países como Japão, Canadá, EUA, Chile, entre outros (VOIGHT; KLEINE, 1975).

Agentes Etiológicos: Os agentes etiológicos são várias espécies do gênero Diphyllobothrium (Bothriocephalus), sendo a nomenclatura do gênero ainda duvidosa, devido ao escasso conhecimento sobre os limites da variação morfológica intraespecífica e os fatores que incidem em tais variações. A espécie mais importante é D. latum (VON BONSDORFF, 1977 apud ACHA; SZYFRES, 1986).

O cestódeo $D$. latum é um verme longo, tendo mais ou menos as dimensões da Taenia solium, medindo as$\operatorname{sim} 8$ a $10 \mathrm{~m}$ de comprimento e apresentando 3 a 4 mil anéis (PESSOA; MARTINS, 1982). 
EIRAS (1994b) cita que D. latum é o maior cestóide que pode parasitar o homem, com os adultos podendo atingir $25 \mathrm{~m}$ de comprimento e conter mais de 4000 proglotes. O homem também é suscetível a $D$. dentriticum, cujo ciclo vital é similar ao de D. latum. O hospedeiro definitivo mais importante é a gaivota, mas outras aves e mamíferos (cães, gatos, ratos) podem desempenhar esse papel. Ao contrário de D. latum, que pode persistir durante muitos anos no intestino do homem, D. dentriticum é expulso após alguns meses. D. cordatum é causador de infecção humana na Groelândia e Japão, pelo consumo de peixes marinhos. Seus hospedeiros definitivos principais são as focas marinhas. Esse parasita também ocorre no cão. No Alasca e no Canadá foram descritos casos humanos por D. ursi, devido ao consumo de salmões do gênero Onchorhynchus. Os principais hospedeiros definitivos desse difilobotrídeo são os ursos $(U r$ sus arctos e $U$. americanus). Outros casos humanos no Alasca e Sibéria devem-se a $D$. dalliae, um difilobotrídeo de cães, raposas e gaivotas, cujos plerocercóides encontram-se no peixe Dallia pectoralis (ACHA; SZYFRES, 1986).

Distribuição e Epidemiologia: Indubitavelmente, D. latum predominou, de início, na região do Mar Báltico, de onde foi disseminado pelos povos dessa região, à medida que migravam para outras partes da Europa e do mundo. Atualmente, D. latum é nativo em muitas zonas da Rússia, países do Mar Báltico, Europa Central e do Sudeste, lago Ngami (Botswana), norte da Manchúria e do Japão, e Nova Gales do Sul, Austrália. Nas Américas, foi identificado no norte de Minnesota, extensas regiões do Canadá e Alasca, bem como nos lagos do sul do Chile e Argentina (CHANDLER, 1926; ACHA; SZYFRES, 1986; FAUST et al., 1987; EIRAS, 1994b). EIRAS (1994b) cita que cerca de dez milhões de pessoas são infectadas por esse parasita.

Segundo ACHA; SZYFRES (1986) e FAUST et al. (1987), o ciclo de infecção mantém-se na natureza por meio da contaminação de rios, lagos e represas com material fecal humano e de outros mamíferos. A contaminação de cursos de água com ovos de $D$. latum permite primeiro a infecção dos copépodos e logo a dos peixes. O homem infecta-se pelo consumo de pescado, ovas e fígado (de peixes) crus, ligeiramente salgados ou submetidos à defumação sem aquecimento suficiente. Praticamente qualquer tecido dos peixes pode ser infectado, e o músculo e as gônadas são os mais importantes para a transmissão ao hospedeiro humano. Os plerocercóides podem parasitar peixes predadores que, nesse caso, terão o papel de hospedeiros paratênicos (EIRAS, 1994b).
A infecção humana não se limita às zonas endêmicas, pois pode ser disseminada pelo transporte e consumo de peixe infectado refrigerado $\mathrm{O}$ homem é o principal hospedeiro definitivo de $D$. latum, mas, na sua ausência, outros mamíferos podem manter o ciclo por meio de um mecanismo de transmissão similar (ACHA; SZYFRES, 1986). Outros mamíferos que podem atuar como hospedeiros principais são cães, suínos, provavelmente ursos e outros animais que se alimentam de peixe (VOIGHT; KLEINE, 1975; FAUST et al., 1987).

Existem certas indicações de que peixes anádromos (que migram anualmente de águas marinhas para águas doces) poderiam ser uma fonte comum de infecção por plerocercóides de diferentes espécies de $D i$ phyllobothrium, tanto para mamíferos terrestres como marinhos. Deste modo, os peixes de um ecossistema de água doce que se alimentam de peixes anádromos poderiam adquirir larvas de origem marinha e os mamíferos terrestres poderiam infectar-se com elas, ao consumi-los crus (ACHA; SZYFRES, 1986).

A Doença nos Animais: O efeito dos plerocercóides de Diphyllobothrium spp. nos peixes foi estudado para inúmeras espécies, variando de ligeiros a pronunciados, podendo provocar a morte dos exemplares parasitados (EIRAS, 1994b). Os efeitos dos plerocercóides de $D$. dentriticum estão, aparentemente, relacionados de modo inverso com a resistência do hospedeiro e a sua capacidade de inativá-los pelo encistamento. Em Coregonus lavaretus, os plerocercóides são envolvidos por cápsulas fibrosas e, mesmo no caso de infecções intensas, não se observam sintomas externos. Já os salmonídeos têm um sistema de defesa menos eficiente e os plerocercóides podem atingir órgãos viscerais importantes antes do encistamento, pelo que a parasitose pode ser fatal. Em C. albula, plerocercóides encistados nunca foram observados, e infecções de pequena intensidade (apenas um ou alguns plerocercóides) podem causar a morte do hospedeiro (BYLUND, 1972 apud EIRAS, 1994b).

RAHKONEN et al. (1996) relataram uma mortalidade crescente de trutas do mar (Salmo trutta m. trutta) e trutas marrons (S. trutta m. lacustris) em uma criação no noroeste da Finlândia. A mortalidade começou quando a temperatura da água aumentou cerca de $12^{\circ} \mathrm{C}$. Haviam de uma a seis larvas de $D$. dentriticum por peixe, onde se encontravam no átrio ou no ventrículo do coração dos animais. Os peixes morreram mostrando sintomas típicos de que as larvas do cestóide estavam bloqueando o orifício atrioventricular. Havia uma miocardite crônica massiva ao redor da larva na parede atrial. Outro 
sinal no peixe morto era a ruptura do átrio do coração. A mortalidade causada por $D$. dentriticum foi de grande importância na mortalidade total da criação.

Em cães e gatos, a infecção por Diphyllobothrium não se manifesta em forma clínica. Na Grã-Bretanha e Irlanda descreveram-se várias epizootias em trutas, provocadas pela infecção de grande número de plerocercóides difilobótricos, talvez diferentes dos de D. latum. Em geral, quando o número de larvas é pequeno, não há danos para o animal, mas uma grande quantidade de larvas pode levar o peixe à morte (ACHA; SZYFRES, 1986).

A Doença em Humanos: O homem pode albergar um ou mais parasitas. D. latum prende-se à mucosa do íleo e à do jejuno, crescendo a uma média de cerca de $5 \mathrm{~cm} /$ dia, e estando em condições de produzir ovos num período de 25-30 dias. Em alguns pacientes que albergam grande número de parasitas, pode haver obstrução mecânica do intestino; em outros pode haver transtornos digestivos, apatia e insensibilidade das extremidades, diarréia, fome ou anorexia, vômito de parasitas, ardor no estômago, tonturas, glossite (VOIGHT; KLEINE, 1975; ACHA; SZYFRES, 1986; FAUST et al., 1987; EIRAS, 1994b). A complicação mais grave consiste em uma anemia megaloblástica, que ocorre em cerca de $2 \%$ das pessoas parasitadas. A sintomatologia é similar à da anemia perniciosa e deve-se ao bloqueio da absorção da vitamina B12 (VOIGHT; KLEINE, 1975; LEITÃO, 1983; ACHA; SZYFRES, 1986; FAUST et al., 1987). O parasita interfere na combinação da vitamina com o fator intrínseco e, deste modo, há uma deficiência em vitamina B12. Freqüentemente, os pacientes são subictéricos, têm febre, edemas, hemorragias e parestesias nas pernas, além dos sintomas supracitados. A anemia megaloblástica ocorre principalmente no grupo de 20 a 40 anos de idade (ACHA; SZYFRES, 1986). Mesmo assim, EIRAS (1994b) afirma que geralmente esse parasita não provoca situações clínicas graves e que é eliminado com o emprego de certas drogas.

Segundo VOIGHT; KLEINE (1975), o homem pode adquirir esparganose ocular causada por larvas plerocercóides de Diphyllobothrium. Os sintomas são edema palpebral, dor e manifestações de irritação. Isso ocorre pela aplicação de carne fresca de rã infectada sobre a conjuntiva dos olhos. O mesmo pode ocorrer se houver essa aplicação em feridas e tecidos injuriados.

Prevenção e Controle: No homem, a prevenção baseia-se na educação sanitária da população para que se abstenha de consumir peixe cru ou insuficientemente cozido; tratamento dos portadores dos cestóides com niclosamida, quinacrina ou praziquantel; congelamento do pescado a $-10^{\circ} \mathrm{C}$ por 24 a 48 horas em áreas endêmicas antes do transporte para o mercado; e medidas de controle contra a contaminação dos rios e lagos (ACHA; SZYFRES, 1986).

FAUST et al. (1987) citam que é necessário um sistema conveniente de esgoto dos dejetos humanos, de tal modo que os ovos viáveis de $D$. latum não possam ter acesso aos cursos de água fria, onde proliferam os hospedeiros intermediários. Uma boa cozedura de todo o peixe proveniente de regiões endêmicas também é importante para evitar-se a doença. Recomenda-se o congelamento à temperatura de $-18^{\circ} \mathrm{C}$ por $48 \mathrm{~h}$ para matar a larva infectante. Finalmente, a vermifugação dos cães pode ser útil. Mesmo assim, não se deve alimentar os animais domésticos com restos de peixe cru (ACHA; SZYFRES, 1986).

\section{Conclusões}

- Embora não haja relatos no Brasil em relação à ocorrência em humanos de zoonoses parasitárias transmitidas por pescado (com exceção da fagicolose), acredita-se que isso se deva à falta de diagnóstico destas doenças, pois foi visto que há a presença de vários destes parasitas zoonóticos nos peixes brasileiros. Para tanto, é necessário alertar os médicos quanto a estas doenças e seus perigos para a saúde humana.

- Uma das principais medidas de prevenção é a abstinência da ingestão de pescado cru ou cozido insuficientemente, embora isso seja praticamente impossível em algumas regiões, devido a fortes hábitos culturais e alimentares.

- É importante realizar um trabalho de educação sanitária e conscientização da população sobre os perigos da ingestão de pescado cru ou mal cozido, principalmente nos dias de hoje, em que consumir pratos contendo pescado cru, como "sushi" e "sashimi", estão na "moda".

- É preciso desenvolver técnicas que melhorem a inspeção e a tecnologia do pescado em relação a estas zoonoses, para uma maior proteção da população, mediante padronização de técnicas eficientes de localização e inativação completa e segura dos parasitas na carne do pescado, pois ainda existem muitas controvérsias a respeito.

- Deve-se evitar a importação de pescado proveniente de regiões onde estas zoonoses sejam endêmicas. 
OKUMURA, M.P.M.; ALEXANDRINO DE PÉREZ, A.C.; ESPÍNDOLA FILHO, A. Principais zoonoses parasitárias transmitidas por pescado - revisão. Revista de Educação Continuada do CRMV-SP / Continuous Education Journal CRMV-SP, São Paulo, volume 2, fascículo 2, p.066 - 080 , 1999.

\section{SUMMARY}

Parasitic zoonosis transmitted by fish are an ever growing problem which calls the attention of researchers and public health authorities because of the health problems caused to the population after raw / rare fish consumption. In Brazil, dishes based on raw fish, such as "sushi" and "sashimis" are greatly consumed because of the influence of oriental culinary. Data show that there are zoonotic parasites in both Brazilian fresh and sea water fish. However, up to the present, there are no reports of human parasitism in Brazil (except for fagicolosis). It is believed that this statistics are related to the absence of diagnosis rather than the absence of the illness itself. Among diseases transmitted to man by fish consumption are anisakiasis; strongyloidiasis; capilariasis; fagicolosis; clonorkiasis and diphylobotriasis, among others. The most important measure to prevent new cases of parasitism is to avoid the consumption of raw / rare fish. There is also the need of educating the population, presenting the potential risk of raw fish consumption and to develop good techniques of inspection and processing of fish infected with parasite, in order to offer healthy and safe food for this population.

Uniterms: fish, zoonosis, parasitism, public health, raw fish consumption.

\section{REFERÊNCIAS BIBLIOGRÁFICAS}

1 - ACHA, P. N.; SZYFRES, B. Zoonosis and communicable diaseases common to man and animals. Washington D., C.: Pan American Health Organization, 1980. (Scientific Publication n. 354).

2 - ACHA, P.N.; SZYFRES, B. Zoonosis y enfermedades transmisibles comunes al hombre y a los animales. 2.ed. Washington, D.C.: Organizacion Panamericana de la Salud, 1986. 989p. (Publicación Científica n. 503).

3 - ADROHER, F.J.; VALERO, A.; RUIZ-VALERO, J.; IGLESIAS, L. Larval anisakids (Nematoda: Ascaridoidea) in horse mackerel (Trachurus trachurus) from the fish market in Granada (Spain). Parasitology Research, v.82, n.3, p.253-6, 1996.

4 - ALEXANDRINO, A.C.; RANZANI-PAIVA, M.J.T.; ISHIKAWA, C.M.; GORGA JR., F.; CARVALHO, M.H.; STECCA, E.A.; ARANA, S.; POLIO, S.M. Histopatologia de baço de tainha da região estuarino lagunar de Cananéia, SP. In: REUNIÃO ANUAL DO INSTITUTO DE PESCA, 1 , São Paulo, 1992. Resumos.

5 - AMATO, J.F.R.; AMATO, S.B. Sulcascaris sulcata (Nematoda, Anisakinae) infecting sea scallops being exposted from southeastern Brazil. Arquivos da Universidade Federal do Rio de Janeiro, Itaguaí, v.5, n.1, p.55-60, 1982.

6 - AMATO, J.F.R.; BARROS, G.C. Anisakíase humana no Brasil - problema inexistente ou não pesquisado. Revista Brasileira de Medicina Veterinária, v.6, n.1, p.12, 1984.

7 - ANTUNES, S.A.; DIAS, E.R.A. Phagicola longa (Trematoda: Heterophyidae) em mugilídeos estocados resfriados e seu consumo cru em São Paulo, SP. Higiene Alimentar, v.8, n.31, p.41-2, 1994.

8 - ANTUNES, S.A.; WIENDL, F.M.; DIAS, E.R.A.; ARTHUR, V.; DANIOTTI, C. Gamma ionization of Phagicola longa (Trematoda: Heterophyidae) in Mugilidae (Pisces) in São
Paulo, Brazil. Radiolology Physical Chemistry., v.42, n.1-3, p.425-8, 1993.

9 - ARAMBULO, P.V.; MORAN, N. Food-transmitted parasitic zoonoses - socio-cultural \& tecnological determinants. International Journal Zoonosis., v.7, p.135-41, 1980.

10 - ASH, L.R. Helminth parasites of dogs and cats in Hawaii. The Journal of Parasitology, v.48, n.1, p.63-5, 1962.

11 - AUDICANA, L.; AUDICANA, M.T.; CORRES, L.F.; KENNEDY, M.W. Cooking and freezing may not protect against allergenic reations to ingested Anisakis simplex antigens in humans. The Veterinary Record, v.140, n.9, p.235, 1997.

12 - BANZÓN, T. Human intestinal capillariasis (Capillaria philippinensis) In: SCHULZ, M.G. (Ed.). CRC handbook. Series in zoonoses. Boca Ratón, Florida: CRC Press, 1982. Section C. V.2.

13 - BARROS, G.C. Larvas de anisakídeos de peixes economicamente importantes da costa do estado do Rio de Janeiro. Revista Brasileira de Medicina Veterinária, v.16, n.5, p.205-8, 1994.

14 - BARROS, L.A. Aspectos patológicos observados nas infecções experimentais de aves piscívoras e mamíferos com metacercárias de Phagicola longus (Ranson, 1920) Price, 1932 (Digenea, Heterophyidae). Itaguaí, Rio de Janeiro, 1993. Tese (Doutorado) Universidade Federal Rural do Rio de Janeiro.

15 - BARROS, L.A.; AMATO, S.B. Acompanhamento clínico de gatos (Felix domestica) infectados experimentalmente com o trematódeo digenético Phagicola longus. In: CONGRESSO BRASILEIRO DE MEDICINA VETERINÁRIA, 22; ENCONTRO NACIONAL DE MELHORAMENTO GENÉTICO E NUTRIÇÃO DE SUÍNOS, 1; ENCONTRO PARANAENSE DE MEDICINA DE PEQUENOS RUMINANTES, 2. Curitiba, 1992. Resumos. 
OKUMURA, M.P.M.; ALEXANDRINO DE PÉREZ, A.C.; ESPÍNDOLA FILHO, A. Principais zoonoses parasitárias transmitidas por pescado - revisão. Revista de Educação Continuada do CRMV-SP / Continuous Education Journal CRMV-SP, São Paulo, volume 2, fascículo 2, p.066 - 080 , 1999.

16 - BARROS, L.A.; AMATO, S.B. Estudo comparativo das lesões observadas em Canis familiaris, Felis domestica e Callithrix jaccnus experimentalmente infectados com o digenético Phagicola longus. In: SEMINÁRIO BRASILEIRO DE PARASITOLOGIA VETERINÁRIA, 8. Londrina, 1993. Anais. Londrina: Colégio Brasileiro de Parasitologia Veterinária, 1993.

17 - BENESON, A.S. EI control de las enfermedades transmisibles en el hombre. Washington D.C.: Organizacion Panamericana de la Salud, 1987. 536p. (Publicación Científica n. 507).

18 - BURSEY, C.R. Eustrongylides tubiflex (Nitzch) encystment in an American eel (Anguilla rostrata) (Le Sueur). Journal Fish Biology, v.21, p.443-7, 1982.

19 - BYLUND, G. Pathogenic effects of a diphyllobothriid plerocercoid on its host fishes. Commentationes Biology., v.58, p.3-11, 1972.

20 - CASTRO, J.M. Extração de cistos de metacercárias de Phagicola Faust, 1920 (Trematoda: Heterophydae) dos tecidos de tainha Mugil Linnaeus, 1758 (Pisces: Mugilidae) mediante emprego das técnicas de digestão enzimática e homogeneização. São Paulo, 1994. 63p. Dissertação (Mestrado) - Faculdade de Medicina Veterinária e Zootecnia da Universidade de São Paulo.

21 - CHANDLER, A.C. Animal parasites and human disease. 3.ed. London: s.n., 1926. p. 245-7.

22 - CHENG, T.C. General parasitology. New York: Academic Press, 1973.

23 - CHENG, T.C. Anisakiasis. In: CRC handbook. Series in Zoonosis: parasitic zoonosis. Boca Raton, Florida: CRC Press, 1982. V. 2. p.37-54.

24 - CHIEFFI, P.P.; LEITE, O.H.; DIAS, R.M.D.S.; TORRES, D.M.A.V.; MANGINI, A.C.S. Human parasitism by Phagicola sp. (Trematoda, Heterophyidae) in Cananéia, São Paulo State, Brazil. Revista do Instituto de Medicina Tropical de São Paulo, v.32, n.4, p.285-8, 1990.

25 - CHITWOOD, M. Phocanema-type larval nematode coughed up by a boy in California. The American Journal of Tropical Medicine and Hygiene, v.24, p.710-1, 1975.

26 - CONROY, G.; CONROY, D.A.; CECCARELLI, P.S. Diseases and parasites detected in grey mullets (Mugilidae) from coastal waters of São Paulo State, Brazil. II. Juvenile silver mullet (Mugil curema Val., 1836). Rivista Italiana Piscicultura Ittiop., v.XX, n.2, p.74-5, 1985

27 - CONROY, G.; PEREZ, K. A report on the experimental infection of a smooth-headed capuchin monkey (Cebus apella) with metacercarie of Phagicola longa obtained from silver mullet (Mugil curema) viscera. Rivista Italiana Piscicultura Ittiop, v.XX, n.4, p.154-5, 1985.

28 - COOPER, C.L.; CRITES, J.L.; SPRINKLE-FASTKIE, D.J. Population biology and behavior of larval Eustrongylides tubiflex (Nematoda: Dioctophymatida) in poikilothermous hosts. The Journal of Parasitology, v.61, n.1, p.1027, 1978.

29 - DAY, M. Fish worm allergy puts diners in hospital. New Scientist, v.153, n.2073, 15 March. 1997.

30 - DIAS, E.R.A.; WOICIECHOVSKI, E. Ocorrência de Phagicola longa (Trematoda: Heterophyidae) em mugilídeos e no ho- mem, em Registro e Cananéia, SP. Higiene Alimentar, v.8, n.31, p.43-6, 1994.

31 - EBERHARD, M.L.; HURWITZ, H.; SUN, A.M.; COLETTA, D. Intestinal perforation caused by larval Eustrongylides (Nematoda: Dioctophymatoidae) in New Jersey. The American Journal of Tropical Medicine and $\mathbf{H y}$ giene, v.40, n.6, p.648-50 (8-336), 1989.

32 - EIRAS, J.C.A importância econômica dos parasitas de peixes. Higiene Alimentar, v.8, n.31, p.11-3, 1994a.

33 - EIRAS, J.C. Elementos de ictioparasitologia. Porto: Fundação Eng. António de Almeida, 1994b.

34 - FAUST, E.C.; BEAVER, P.C.; JUNG, R.C. Agentes e vectores animais de doenças humanas. Porto: Fundação Calouste Gulbenkian, 1987.

35 - FRESH, J.W.; CROSS, J.H.; REYES, V.; WHALEN, G.E.; UYLANGCO, C.V.; DIZON, J.J. Necropsy findings in intestinal capillariasis. The American Journal of Tropical Medicine and Hygiene, v.21, n.2, p.169-73, 1972.

36 - GEORGI, J.R. Parasitologia veterinária. São Paulo: Manole, 1988.

37 - HASWELL-ELKINS, M.R.; SITHITHAWORN, P.; ELKINS, D. Opisthorchis viverrini and Cholangiocarcinoma in Northeast Thailand. Parasitology Today, v.8, n.3, p. 86-9, 1992.

38 - HUSS, H.H. Garantia da qualidade dos productos da pesca. Roma: FAO, 1997. (Documento Técnico sobre as Pescas 334).

39 - INFORME DE UN COMITÉ DE EXPERTOS DE LA OMS CONVOCADO EN COOPERACIÓN COM LA FAO. Higiene del pescado y los mariscos. Ginebra: FAO/ OMS, 1973. (Organización de las Naciones para la Agricultura y la Alimentación, Roma, 1975).

40.KATES, S.; WRIGHT, K.A.; WRIGHT, R. A case of human infection with the cod nematode Phocanema sp. The American Journal of Tropical Medicine and Hygiene, v. 22 , n.5, p.606-8, 1973.

41 - KHAMBOONRUANG, C. On emerging problems in food-borne parasitic zoonosis: impact on agricultures and public health. Southeast Asian Journal Tropical Medicine and Public Health, n.22, p.1-7, 1991. Supplement.

42 - KLIKS, M.M. Anisakiasis in the Western United States: four new case reports from California. The American Journal of Tropical Medicine and Hygiene, v.32, n.3, p. 526-32, 1983.

43 - KNOFF, M. Helmintofauna de tainhas Mugil spp. (complexo Liza-Platanus) do litoral do Estado do Rio de Janeiro. Itaguaí, Rio de Janeiro, 1990. Dissertação (Mestrado) - Universidade Federal do Rio de Janeiro.

44 - LEITÃO, J.S. Parasitologia veterinária. 3.ed. Lisboa: Fundação Calouste Gulbenkian, 1983. V. I-II.

45 - LICHTENFELS, J.R.; BRANCATO, F.P. Anisakid larva from throat of an Alaskan Eskimo. The American Journal of Tropical Medicine and Hygiene, v.25, n.5, p.691-3, 1976.

46 - LITTLE, M.D.; MacPHAIL, J.C. Large nematode larva from the abdominal cavity of a man in Massachusetts. The 
American Journal of Tropical Medicine and $\mathrm{Hy}$ giene, v.21, n.6, p.948-50, 1972.

47 - LITTLE, M.D.; MOST, H. Anisakid larva from the throat of a woman in New York. The American Journal of Tropical Medicine and Hygiene, v.22, n.5, p.609-12, 1973.

48.LUQUE, J.L. Estudo preliminar da fauna parasitária do pargo, Pagrus pagrus (Osteichthyes: Sparidae), do litoral do Estado do Rio de Janeiro, Brasil. In: ENCONTRO BRASILEIRO DE PATOLOGIA DE ORGANISMOS AQUÁTICOS, 4. São Paulo, 1996. Resumos. São Paulo: ABRAPOA, 1996. p.6.

49 - OSHIMA, T. Anisakiasis - Is the Sushi Bar Guilty? Parasitology Today, v.3, n.2, p.44-8, 1987.

50 - PANESAR, T.S.; BEAVER, P.C. Morphology of the advancedsatage larva of Eustrongylides wenrichi Canavan 1929, ocurring encapsulated in the tissues of Amphiuma in Louisiana. The Journal of Parasitology, v.65, n.1, p.96-104, 1979.

51 - PAPERNA, I. Hosts, distribuition and pathology of infections with larvae of Eustrongylides (Dioctophymidae, Nematoda) in fishes from East African lakes. Journal Fish Biol.ogy, v.6, p.67-76, 1974.

52 - PESSOA, S.B.; MARTINS, A.V. Parasitologia médica. 11.ed. Rio de Janeiro: Guanabara Koogan,.1982. p.443-6.

53 - RAHKONEN, R.; AALTO, J.; KOSKI, P.; SÄRKKÄ, J.; JUNTUNEN, K. Cestode larvae Diphyllobothrium dendriticum as a cause of heart disease leading to mortality in hatcheryreared sea trout and brown trout. Diseases of Aquatic Organisms, v.25, p.15-22, 1996. Abstract. Internet: $<$ http://www.int-res.com/int-res/dao/25/ d025p015.abs.html>

54 - REGO A.A. Eustrongylides (Nematoda: Dioctophymidae), potencial importância em piscicultura. In: SIMPOSIO LATINOAMERICANO DE AQUICULTURA, 6; SIMPÓSIO BRASILEIRO DE AQUICULTURA, 5, Florianópolis, SC, 1988 Resumos. Florianópolis: Associação Latinoamericana de Aquicultura-ALA; Associação Brasileira de Aquicultura- ABRAq.

55 - REGO, A.A.; SANTOS, C.P. Helmintofauna de cavalas, Scomber japonicus Houtt, do Rio de Janeiro. Memórias do Instituto Oswaldo Cruz, Rio de Janeiro, v.78, n.4, p.443-8, 1983.

56 - REGO, A.A.; VICENTE, J.J.; SANTOS, C.P.; WEKID, R.M. Parasitas de anchovas, Pomatomus saltatrix (L.) do Rio de Janeiro. Ciência e Cultura, v.35, n.9, p. 1329-36, 1983.

57 - RIM, H.J.; KIM, K.H.; JOO, K.H.; KIM, S.J.; EOM, K.S.; CHUNG, M.S. The infestation states and changing patterns of human infecting metacercarie in freshwater fish in Kyongsang-do and Kyonggi-do, Korea. Korean Journal Parasitology, v.34, n.2, p.95-105, 1996. Abstracts. Internet: <http://www.sun.hallym.ac.kr>
58 - SANTOS, C.A.L. Prevention and control of food borne trematodes in cultured fish. INFOFISH International, n.2, p.57-62, 1995.

59 - SÃO CLEMENTE, S.C.; MARQUES, M.C.; SERRA-FREIRE, N.M.; LUCENA, F.P. Análise do parasitismo de peixe espada Trichiurus lepturus L. do litoral do Rio de Janeiro Brasil. Parasitologia al Día, v.19, p.146-9, 1995.

60 - SÃO CLEMENTE, S.C.; SILVA, C.M.; LUCENA, F.P. Sobreviência de larvas de anisaquídeos de peixe espada, Trichiurus lepturus (L.), submetidos aos processos de salmouragem e cocção. Revista Brasileira de Ciência Veterinária., v.3, p.79-80, 1996.

61 - SARAIVA, M.E.V. Estudio de diferentes metodos de conservación sobre la sobrevivencia de metacercarias de Phagicola longa (Ransom, 1920) Price, 1932 en los tejidos de la lisa criolla (Mugil curema Val, 1836). Caracas, Venezuela, 1991. Trabajo especial (Grado) - Universidadad Central de Venezuela.

62 - SHIRAZIAN, D.; SCHILLER, E.L.; GLASER, C.A.; VONDERFECHT, S.L. Pathology of larval Eustrongylides in the rabbit. Journal of Parasitology., v.70, p.803-6, 1984.

63 - SINDERMANN, C. J. Principal diseases of marine fish and shellfish. California: Academic Press, 1990.

64 - SORNMANI, S. Control of Opisthorchiasis through Community Participation. Parasitology Today, v.3, n.1, p.313, 1987.

65 - THATCHER, V.E.; NETO, J.B. Diagnóstico, prevenção e tratamento das enfermidades de peixes neotropicais de água doce. Revista Brasileira de Medicina Veterinária, v.16, n.3, p.111-28, 1994.

66 - TORRES, P.; PEQUEÑO, G.; FIGUEROA, L. Nota preliminar sobre Anisakidae (Railliet y Henry, 1912) Skrajabin y Karokhin, 1945 en alguns peces de consumo habitual por la población humana de Valdivia (Chile). Boletin Chileno de Parasitologia., v.33, p.39-46, 1978.

67 - VOIGHT, M.; KLEINE, P. Zoonosis. Zaragoza: Acribia, 1975. Cap. 5. p.269-76.

68 - VON BONSDORFF, B. Diphyllobotriasis in man. Londres: Academic Press, 1977.

69 - WATTEN, R.H.; BECKNER, W.M.; CROSS, J.H.; GUNNING, J.J.; JARIMILLO, J. Clinical studies of capillariasis philippinensis. Transactions of the Royal Society of Tropical Medicine and Hygiene, v.66, n.6, p.828-34, 1972.

70 - WITTNER, M.; TURNER, J.W.; JACQUETTE, G.; ASH, L.R.; SALGO, M.P.; TANOWITZ, H.B. Eustrongylidiasis - a parasitic infection acquired by eating sushi. The New England Journal of Medicine, v.320, n.17, p.1124-6, 1989.

\section{AGRADECIMENTOS}

Ao Prof. Dr. Sérgio Carmona de São Clemente da Faculdade de Veterinária da Universidade Federal Fluminense (UFF), que gentilmente cedeu as ilustrações. 